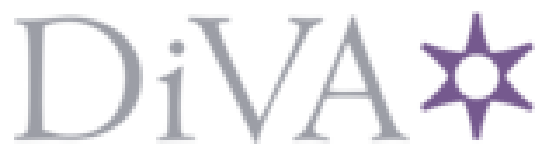

http://www.diva-portal.org

This is the published version of a paper published in Gerontechnology.

Citation for the original published paper (version of record):

Larsson, E., Larsson Lund, M., Nilsson, I. (2017)

Developing social contact and participation in social activities: Seniors experiences

from a social Internet-based intervention process

Gerontechnology, 16(2): 101-108

https://doi.org/10.4017/gt.2017.16.2.005.00

Access to the published version may require subscription.

N.B. When citing this work, cite the original published paper.

Permanent link to this version:

http://urn.kb.se/resolve?urn=urn:nbn:se:umu:diva-114432 


\title{
Developing social contact and participation in social activities: Seniors' experiences from a social internet-based intervention process
}

\author{
Larsson Ellinor $\mathrm{PhD}^{\mathrm{a}, *}$ \\ Larsson-Lund Maria $\mathrm{PhD}^{\mathrm{b}}$ \\ Nilsson Ingeborg $\mathrm{PhD}^{\mathrm{a}}$
}

\begin{abstract}
aDepartment of Community Medicine and Rehabilitation, Occupational Therapy, Umeå University, Umeå, Sweden; ${ }^{b}$ Department of Health science, Occupational therapy, Luleå University of technology, Luleå, Sweden; *Corresponding author: ellinor.larsson@umu.se
\end{abstract}

\begin{abstract}
L. Ellinor, L.L. Maria, N. Ingeborg. Developing social contact and participation in social activities: Seniors' experiences from a social internet-based intervention process. Gerontechnology 2017;16(2):101-108; https://doi.org/10.4017/gt.2017.16.2.005.00 Objective To explore seniors' experiences of the intervention process after participating in a social internet-based occupational therapy intervention. Method A qualitative interview study was conducted. Twelve women and 3 men (66-87 years old), from the completed intervention study participated. The study was placed in northern Sweden. Data were collected through semi-structured interviews. The interviews were analyzed using the constant comparative method, and two categories with subcategories were generated in the analysis. Results The seniors experienced a need to participate in social internet-based activities (SIBAs) due to their decline in social activities and the ever-increasing digitalization of society. In the intervention process, the seniors' experiences reflected two divergent directions. The first consisted of seniors who had experiences of being hampered in participating in the SIBAs in the intervention process. They did not completely reach their intervention goals, but they did describe increased ability to use SIBAs and increased self-reliance. The other direction of the process reflected experiences of reaching their goals in the intervention, and they developed habitual participation in SIBAs as well as increased participation in social activities outside the Internet. Conclusion The social internet-based intervention can support seniors to overcome the obstacles that prevent them from participating in SIBAs. By participating in SIBAs, the seniors might enrich their social activities and social contacts both on the Internet and outside, if the intervention is individually targeted to meet their needs.
\end{abstract}

Keywords: social activities, internet-based intervention, seniors, social contacts

Seniors' restricted participation in internet-based activities (IBAs) needs to be improved to support their inclusion in today's digital society ${ }^{1-3}$. Due to functional declines ${ }^{4}$, lack of abilities, and lack of accessibility ${ }^{1,5,6}$, becoming older might indicate limited use of technology in everyday life. A lack of participation in IBAs might reduce seniors opportunities to access daily activities, available in alternative ways via the Internet ${ }^{7}$. The use of social IBAs (SIBAs) (i.e. social medias or online video calls) has increased rapidly in the Swedish population, but seniors have not become users to the same extent as younger generations ${ }^{2}$. SIBAs might be beneficial for seniors' experiences of participation in society ${ }^{8}$, interactions with younger generations, and sharing of everyday life events with family and friends 9,10 .

SIBAs might also be useful for enhancing the reduced social activities and social contacts ${ }^{9,11}$ that can occur due to retirement ${ }^{12}$, or the death of a spouse $^{13}$. Life-changing events like these might

negatively impact seniors' satisfaction with their social contacts and evolve into experiences of loneliness $^{14,15}$. Loneliness is also indicated to be relieved by participation in SIBA interventions, i.e. by giving support and facilitating social contact between seniors living in nursing homes and their families, by use of online video-conference meetings ${ }^{17}$ and other social medias ${ }^{16}$. Even though positive indications exist ${ }^{11,18}$, studies have also identified barriers to participation in SIBAs among seniors, including undefined personal goals and difficulty participating in SIBAs without introduction and support ${ }^{11}$. Insecurity and lack of knowledge on how to handle the limited privacy and sometimes undesirable content associated with online activities might also cause barriers for the seniors ${ }^{18}$.

To address the specific needs that have been identified in the studies mentioned above, we have evaluated the effects of an occupational therapy SIBA intervention, for overcoming se- 
curity, and technological barriers and support reduced loneliness, social activities and participation. The intervention focuses on individually adapted and goal-directed actions to facilitate seniors' individual and group-based participation in SIBAs ${ }^{19,20}$. The intervention has shown positive results, including reduced self-reported loneliness and a potential increase in satisfaction with social contacts on the Internet. However, it is not known from the available SIBA intervention studies ${ }^{16,17}$ how the participants experience the intervention process to begin participating in SIBAs. Nor is it known which barriers - such as privacy and security issues ${ }^{21}$-the seniors are facing in the intervention process. It is important to understand the participants' experiences of the intervention so as to provide evidence for the worth of the intervention ${ }^{22}$ and to develop clientcentered interventions ${ }^{23}$. The aim with this study was to explore seniors' experiences of the intervention process after participating in a social internet-based occupational therapy intervention.

\section{Method}

A qualitative interview study was designed to capture the seniors' experiences of the intervention process. The data were collected by qualitative, semi-structured, open-ended questions ${ }^{24}$ and analyzed with the constant comparative method described by Strauss \& Corbin ${ }^{25}$.

The analysis method was also chosen to capture the seniors' experiences of similarities and differences in the meanings, interactions, and actions during the intervention process. Ethical approval was given from the ethics committee in Umeå, Sweden (Dnr 2011-109-31 M).

The informants in this study were recruited from the earlier explorative randomized controlled intervention study, which is more thoroughly described elsewhere ${ }^{20}$. In brief, the former explorative intervention study had a crossover design and involved 30 participants who were randomized to a fall or spring group and received three months of intervention during the intervention period. The intervention in that study aimed to reduce seniors' vulnerability to loneliness through participation in SIBAs. The individually adapted, and client-centered occupational therapy SIBA intervention was planned in collaboration with the occupational therapists (OTs) and was based on the seniors' individual goals for the SIBA intervention. The intervention program followed a combination of a group-based and individual format. An online video-phone call was used for all of the group meetings. The OTs combined the groups after the first individual meeting based on i.e. seniors' interests, age and gender. Assignments were given in advance of the group meetings with tasks to accomplish and subjects to discuss at the meeting, one task could be to find a debate article about current topics in society and present it at the meeting. Other SIBAs were used to meet the individuals' goals, and support from the OTs was given individually in the seniors' homes or remotely via email, video-phone call or telephone when needed. The groups met online every $2^{\text {nd }}$ week for one and a half hour, and the individual support was offered every week in their homes. None of the authors of the present article were involved in the intervention process with the seniors.

\section{Procedure and selection of informants}

In this study, participants from the previous explorative intervention study ${ }^{20}$ were recruited using a purposeful sampling method. The study took place in a mid-size city in northern Sweden. The participants had Internet access at home and had experiences of using the Internet and of participating in SIBAs after the intervention. To explore potential differences in the seniors' intervention processes, participants from both sexes were included. In addition, a variety of ages and experience using computers and the Internet as well as informants who described having achieved their goals during the intervention and those who did not were included. The sampling was done by the first author using complementary information from the intervening OTs involved in the previous explorative intervention study.

The enrollment of the informants to this interview study was initiated two weeks after the explorative intervention study was completed. Initially, an invitation letter was sent out to four seniors from the previous intervention study with information about the study purpose and voluntary participation. These four were then contacted by telephone (about one week later) and asked to give their consent to participate. If they approved, a time and place for the interview was decided based on the seniors' choice. The interviews were conducted during the continued enrolment, which was repeated until 15 seniors had been included and the data were considered to be sufficiently rich to ensure the quality of the study. In total, the invitation letter was sent to 20 out of the 30 available seniors from the earlier intervention study. Reasons for declining participation included lack of time, sickness, and having no interest in participating.

\section{Informants}

Fifteen seniors ( 3 men and 12 women, aged 66-87 years) were included. Ten of them were living alone and five were cohabiting. Ten had participated in the intervention in the fall and ended the intervention six months prior to this qualitative interview study, and five participated in the spring group and ended the intervention two weeks before this study. 


\section{Data collection}

The interview guide that was used for the data collection was based on open-ended questions, including the seniors' reasons for being interested in participating in SIBAs and how the intervention process and the support they received during the intervention process was experienced. Moreover, consequences and influences on daily life during and after the intervention process were also explored in the interview questions. All interviews were conducted in the seniors' homes, were audio recorded, and lasted between 30 and 60 minutes. During the data collection process, the audiotaped interviews were listened through to support the understanding of the participants' experiences and to alter the interview questions if needed. All interviews were transcribed verbatim after all the interviews had been conducted, and thereafter the analysis of the data was initiated.

\section{Data analysis}

All authors contributed and took part in the constant comparative analysis ${ }^{25}$. The interviews were read through several times to identify similarities and differences reflected in the seniors' experiences of the intervention process and their interactions and actions during the process. Open coding was then used to identify pieces of the text with meaning related to the purpose of the study. The codes with similar content were brought together into preliminary categories to reflect the participants' experiences with the intervention process. For each preliminary category, memos were written to record early thoughts and interpretations of the text to support the further categorization. The first author performed the initial preliminary analysis that was discussed and compared with the understanding of the third author. In that deliberation, ideas on how to develop and structure the preliminary categories were formed and changed, which were then reviewed by the second author. The first author then continued on to axial coding where similarities and differences in the individual processes were combined into preliminary sub-categories. Later in the analysis, both the second and the third authors contributed with deliberations about the preliminary categories including the sub-categories. Also, both the preliminary and the established categories with sub-categories were compared with the content of the interviews to ensure that the results were grounded in the data. The analysis process continued until a shared understanding was reached between all the authors. Two categories with sub-categories were generated in the analysis process, and these are described in the results section. The manuscript was subjected to peer-review from research colleagues as advised to increase the credibility of the results ${ }^{26,27}$.

\section{Results}

Two categories were generated in the analysis process. The first reflected how the intervention process emanated from a mutual standpoint and how the seniors' social decline combined with increased digitalization in society evoked a need to change prior to the intervention. The second reflected differences in whether the seniors achieved their goals for the intervention, which are described in the four sub-categories (two for each direction of the intervention process) (Figure 1).

\section{Social decline and societal digitalization evoke a need to change}

In this category, the seniors' experiences reflected a need to change and to develop their social life by participating in SIBAs. The need to change emanated from experiences of lifechanging events - such as the loss of a spouse, a change of residence or retirement - that had caused a reduction in significant social contacts. The seniors expressed interest in participating in SIBAs because of the possibility to increase social contacts, as illustrated in this quotation: "Because I was lonely, I wanted to learn...at my age, it is not that easy to come into contact with new people." The seniors' experiences also reflected uncertainties about how to properly initiate social contact via SIBAs, including how much they should reveal about themselves and what to write. Their experiences also reflected the idea that they were required to participate in SIBAs to be able to interact with others. The readiness to try SIBAs was also influenced by thoughts that SIBAs could be interesting or that they needed the ability to manage such activities due to increased digitalization in society. Some had also been introduced to SIBAs by relatives and had gained an awareness of different social medias that could be used. When the seniors were reflecting on their experiences in using computers and the Internet before the intervention, they expressed various levels of skills. The seniors had used and were interested in IBAs, but some were more satisfied and some were less satisfied with their technological skills as illustrated by the following two quotations with contrasting experiences. One senior who was more familiar with the use of IBAs expressed a sense of familiarity: "It was based on using the computer, and I had been doing that for a couple of years so that was easier. Searching for things on the computer and receiving e-mail and such things is something I had been doing". The opposite feeling was expressed by another senior: "I'm not that skilled with computers and I always get so scared, and wonder how I close this [program] without removing everything." 


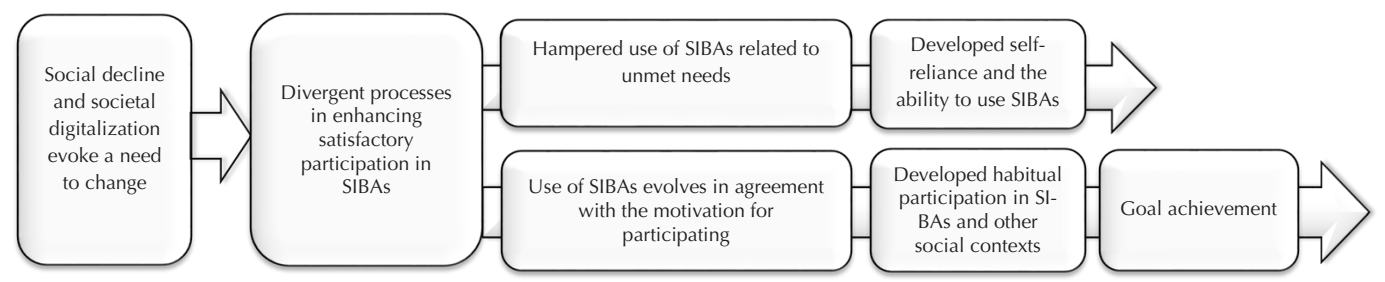

Figure 1. Visualization of the seniors' divergent intervention processes, at first towards the development of self-reliance and the ability to use SIBAs. Then the second direction that lead to goal achievement and habitual participation in SIBAs.

\section{Divergent processes in enhancing satisfactory participation in SIBAs}

This category and its four sub-categories reflect how the seniors' intervention processes developed in two divergent directions. On the one hand were those who experienced hampered participation in SIBAs but who developed increased abilities to use SIBAs and self-reliance. On the other hand, there were those whose participation in SIBAs evolved into experiences of goal-achievement and satisfactory habitual participation in social activities both on the Internet and in other social contexts.

\section{Hampered use of SIBAs related to unmet needs} From the seven seniors who experienced that their use of SIBAs was hampered in the intervention process; four of them had participated in the intervention in the fall and three in the spring. Five of them were living alone and two were cohabiting. The seniors in this direction described difficulties related to themselves as a person, for example, memory loss or sickness, or to technical issues (e.g., insufficient Internet connection) or social aspects such as difficulties in finding suitable friends. Other difficulties mentioned by the seniors were that they had not always prioritized the intervention or they had been restricted in fully participating by other conditions in their life situation during the intervention process. One reason given for not fully participating was having too little time due to too many other obligations and activities, and this led to the feeling that they should have contributed more during the intervention. One senior described a set of difficulties that hampered the intervention process: "As I said, I was being lazy because I was preoccupied with other things and then I got sick in the middle of all this, and then you put that aside [use of SIBAs]. So, unfortunately, it did not become what I had expected it to become, and maybe it had something to do with me as well, that I was too lazy." The seniors' experiences from the individual meetings with the OTs also reflected that additional time could have been beneficial for them to progress further in the intervention process towards their goals.
The seniors that progressed in this direction and experienced difficulties that hampered them in their progression did not always have well-defined motives for participating in SIBAs, as one senior explained: "I wanted to learn just because everybody else had it [the computer and Internet], the whole family had it and others were talking about how you should get 'it' when you become old". These seniors' experiences also reflected that the online video calls had not been made independently during the process, and how the group meetings had been less satisfactory. This was due to problems with the technology and difficulties in finding others in the group who met their expectations of a potential friend: "I do not think that there was anything wrong with the idea [to meet each other online]... I think that it was in the [group members] who were supposed to work together... and it can be really difficult for you to combine us, you do not know us." The seniors' experiences also reflected barriers to participate in SIBAs that were related to a lack of privacy online and to not being completely confident in how to limit the spread of personal information on the Internet.

Developed self-reliance and the ability to use SIBAs The seniors who were hampered in their intervention processes did not achieve all aspects related to their goals. Their experiences did, however, reflected that the OTs had supported them in learning and developing their ability to use SIBAs, and this led to an increased belief in their own abilities. After the intervention, it was also reflected that the participants had gained the power to decide for themselves if they wanted to participate: "Yes, now it is up to you, that you get going... it's all up to me to work with this. I have received the tools, now I just have to start using them." Their experiences also reflected that they could experience it as demanding to change previous habitual activities and to establish new ways to participate in activities, and they talked about themselves as being 'too old', meaning that changes could require more time and engagement than when they were younger. 
Although their self-reliance and abilities to use SIBAs were experienced as being increased, many barriers were still prominent after the intervention. For example, they often had to wait for someone to help them with technical problems or they had no headset to use for the video-calls after the intervention ended. They often did not fully recognize the personal benefits of participating in SIBAs, and they also felt that SIBAs could be complicated to understand and use, as one senior described the complexity of one social media: "It is difficult to grasp, you jump between different persons like your brother, and his kids... apparently you get a birthday reminder as well".

When reflecting on their use of SIBAs for social contact and interaction, they did not experience that the SIBAs had a prominent impact on their social life. This was related to a limited number of people in their present social network who participated in SIBAs and the fact that many of their friends and relatives were not yet online. Another reason was that they had not searched actively for social contacts or made any online social contacts that were experienced as suitable or interesting to them. The seniors often preferred to meet others outside the Internet, and they described how the quality of social interactions was different outside the Internet. Despite not achieving all of their goals, the seniors' experiences in this direction of the intervention process reflected that their development towards participating in SIBAs had not come to an end. They might continue to learn how to use SIBAs because they thought that such abilities are needed in today's digital society.

Use of SIBAs evolves in agreement with the motivation for participating

The eight seniors' in this other direction in the intervention experienced progress towards their goal achievements by support of the OTs. Six of them had participated in the intervention in the fall and two in the spring. Five of them were living alone and three were cohabiting.

The support they received in how to participate in SIBAs during their individual sessions was to be sufficient for their needs: "You never felt rushed, or that "you should get that", and I suppose that this made it fun when [the occupational therapist] was here." The seniors' experiences reflected how they tried to increase their abilities by repeating the tasks between the individual meetings and by taking their own initiative to make social contacts and to participate in SIBAs. The seniors' experiences also revealed that they valued being in charge of their learning and that they were entrusted to perform the tasks by themselves: "There is no point if someone is just showing you, you won't learn from that. No, you have to press the buttons [on the computer] yourself; it is the only way, I think, to learn.

For the online group meetings, they experienced how easy it was to participate even though technical problems could occur. The group meetings provided satisfactory social contacts-and they appreciated meeting others online-and the assignments that needed to be completed before the meetings were experienced as pleasant. They also expressed that the level of instruction was suitable for them. The seniors' experiences of the learning process during the intervention were compared with other formats, like previous courses, and it was described how such courses had often not been suitable for their needs. In the courses, they had experienced that they were often left behind because the other participants had been too young, too skilled or learned too fast. The seniors also described how they avoided the problem of transferring knowledge from another setting with different technical equipment's because they used their own computer at home during this intervention.

\section{Developed habitual participation in SIBAs and other social contexts}

These seniors expressed how they had reached their goals with the intervention. Similarly, to the seniors who took the other direction in the intervention process, they also developed increased self-reliance and the ability to use SIBAs, but they continued to develop a more habitual participation in SIBAs as a way to develop social contacts both on the Internet and offline. The seniors told how they were satisfied with their participation after the intervention, and they experienced having sufficient social contacts and being able to participate in different SIBAs as they wished to (i.e. both international and age-adapted social medias). This more habitual use was reflected as they continued to visit social forums for social contacts and to initiate and develop the contacts, for example, with friends, family, and those living far away as well as with younger generations. The participation in SIBAs was described as facilitating interactions and social contacts, for example, with grandchildren who might not otherwise respond to traditional mail outside the Internet. Brief messages were also sent via SIBAs to decide things like when and where to meet for social activities outside the Internet. Their descriptions revealed that they continued to meet their social contacts from the Internet in other contexts, i.e. for coffee, to travel together, to go to the theater, or to go dancing together. The SIBA participation had contributed with other ways to meet and had contributed with shared activities that brought them together: "We had lunch one time, and [before the lunch] we used a social forum online to decide what restaurant 
to meet at. I have met them, so now I can say hi to them, and kind of know them now".

The seniors' experiences revealed the necessity to initiate social contact and to be active online and not just wait for others to contact them. The social contact via the Internet was experienced as valued and supplementary to offline social activities, but the offline social contacts were described as something 'different': "Being able to see each other and to see each other's body language and other expressions is something completely different from what one experiences online."

The online video phone call that was used for the group-based part of the intervention (and used individually if suitable to the participant's goals) was also used after the intervention by these seniors, and for some it had become one way to habitually participate in social activities. For example, one senior described that after the intervention the online video-phone call supported maintained regularly daily contact with a family member living far away. The video-phone call had contributed to another dimension in their relationship because they talked more often and also saw each other. The seniors also experienced that they now had a wider perspective on the world and that it was easier for them to make contact with people from around the world. Experiences of loneliness or lack of satisfactory social contacts were reflected as being eased for some of the participants, because they could participate in SIBAs any time of the day or week, for example, on a rainy day when feelings of loneliness might be more prominent.

The seniors who progressed in this direction in the intervention process felt that they were more prepared to handle the lack of privacy on the Internet. They had also become more confident: "I have overcome many barriers...you are more confident and develop a sense of daring and of experiencing new things".

\section{Discussion}

The seniors who participated in the occupational therapy SIBA intervention all had similar needs and interest prior to the intervention, but during the intervention they developed in different directions in relation to their goals. Based on the findings presented here, it is difficult to fully understand why the intervention process took two different directions because the participants received similar individually adapted support. The fact that all of them did not benefit to the same extent might be related to aspects in their daily lives that prevented them from fully participating in the intervention, that they experienced personal deficits that were not identified or accounted for in the intervention (such as memory losses), or that the time frame was too limited for them to develop the habit of participating in the SIBAs. Also, some of the seniors might have felt that the introduced SIBAs did not meet their expectations of needed and meaningful activities. This is supported in previous research ${ }^{28,29}$ that indicates that satisfactory goal achievement requires that the clients' individual needs are identified and met, and that the intervention is individually tailored during the intervention process to support participation in SIBAs ${ }^{8,30}$.

The results from present study reflected that some seniors reached their goals with the occupational therapy SIBA intervention and enriched their social activities, social contacts, and participation in other social contexts. These aspects are positive indications of the intervention program ${ }^{20}$. The intervention was also reflected as client-centered by the experiences of the seniors, mainly by those who reached their goals with the intervention. They described that they had found that the OTs method of learning suited their needs, especially in comparison with previous courses they had taken in which the general content did not facilitate their learning. In this study, the seniors' experiences also reflected how the SIBAs had become a shared activity that brought them together in other social settings outside internet. This positive results are supported by other research ${ }^{31}$, indicating that reduced experiences of loneliness might be achieved by taking active part in social activities and by being supported in sharing experiences, having a sense of belonging to a group, and making social contacts. Both directions of the intervention process also described the social contact outside the Internet as something 'different' in comparison with the online contacts, but that it was still a valuable complementary contact. To explore the quality in social interactions and contacts on internet were not a primary focus in this research and should be explored further.

From earlier research ${ }^{11,18}$, security and privacy issues were assumed to become hindering aspects to the intervention process. The results from this study indicated that the seniors were aware of such issues and that they considered them to be troublesome, although they (especially those who reached their goals) achieved feelings of increased abilities to handle such issues when participating in SIBAs. Enhanced participation in SIBAs might help overcome barriers related to the digital gap and might support increased participation in today's digitalized society ${ }^{1}$. The seniors in this study were prepared to participate in SIBAs, and they were influenced to do so by a decline in their social networks and by the increasing prevalence of the technology that makes up much of modern daily life. This SIBA 
intervention might therefore have the potential to be used worldwide to support seniors' digital inclusion and reduced loneliness.

For the group meetings, the seniors had different preferences that might have influenced their satisfaction with the social contact in the group. Some were satisfied, while others described that the meetings did not meet their preferences for social contact. How to create beneficial groups for the online meetings is a suggestion for future studies because the social contact was valued by some of the participants and might be one way to reduce vulnerability to loneliness. Thus, how to more clearly define the goals, plans, and combinations of group members should be further explored, as suggested for therapeutic activity group formats $\mathrm{s}^{32}$, and in order to better understand how the online environment influences these interactions ${ }^{33}$.

The trustworthiness ${ }^{34,35}$ of the results has been enriched by the involvement of several researchers in the analysis process and by the careful interpretations of the data to ensure that the results originate from the seniors' experiences. This group of participants initiated and tried to create a change in their social context and activities and might therefore be a highly motivated group in comparison with the general population. The transferability $^{34,35}$ of this study is thus limited to seniors (especially women) in a Swedish context who are vulnerable to experiences of loneliness but who are actively searching for ways to change that. The seniors had the ability to participate in IBAs but needed support to advance their knowledge further. A possible limitation in the data is the variation in time (from two weeks

\section{Acknowledgements}

This work was supported by the Swedish Research Council's Strategic Research Programme in Care Sciences at Umeå University; the Swedish Research Council's Linnaeus Grant (no 2006-21576-36119-66); the C Wikström Grant; the Interreg IV A Botnia-Atlantica Programme (in collaboration with the Regional Council of Ostrobothnia; Novia University of Applied Sciences (Finland); Åbo Akademi University (Finland); Umeå Municipality (Sweden); Umeå University (Sweden)).

\section{References}

1. Digidel. Increased digital participation. In swedish: Ökad digital delaktighet. Stockholm, 2013; http:// digidel.se/wp-content/uploads/2015/09/digidel_slutrapport_2013.pdf ; retrieved March 8, 2017

2. Findahl O. The retirees and internet. In Swedish: Pensionärerna och internet. Stockholm, 2014; https://www.iis.se/docs/Pensionarerna_och_internet_2014.pdf; retrieved February 2, 2017

3. Nilsson I, Townsend E. Occupational justice - Bridging theory and practice. Scandinavian Journal of to six months) since they participated in the occupational therapy SIBA intervention. A longer time period since the intervention might have made it more difficult for the seniors to recall details from their intervention processes, and for those who participated more recently changes over time after the intervention might not have been captured. In the earlier intervention study, no significant differences in outcome between the fall and the spring group was detected in relation to group allocation ${ }^{20}$. This qualitative exploration of the seniors' experiences with the intervention process has provided a better understanding of the aspects that hindered or facilitated their participation in SIBAs. This knowledge is important for the further development of this intervention so that it can better support seniors to develop habitual participation in social activities and social contexts both on the Internet and offline.

\section{Conclusion}

This exploration of the seniors' experiences of the SIBA intervention indicated that the seniors should be carefully supported in identify the meaning of the SIBAs in the intervention process. The intervention should be individually adapted in terms of time and content so as to reduce the difficulties in participating in SIBAs. When these difficulties are accounted for, the intervention might support habitual participation in social activities and enhance social contacts both on the Internet and offline. To further advance this intervention, the goal setting, client-centeredness, individual adaptation, and individual support should be emphasized and constantly evaluated throughout the intervention process.
Occupational Therapy 2010;17(1):57-63; https://doi. org/10.3109/11038120903287182

4. Hedman A, Nygård L, Almkvist O, Kottorp A. Amount and type of everyday technology use over time in older adults with cognitive impairment. Scandinavian Journal of Occupational Therapy 2015;22(3):196-206; https:// doi.org/10.3109/110381 28.2014.982172

5. $\mathrm{Ng} \mathrm{CH}$. Motivation among older adults in learning computing technologies: A grounded model. Educational Gerontology 2007;34(1):1-14; https://doi. org/10.1080/03601270701763845

6. Smith A. Older adults technology use: Adoption is increasing, but many seniors remain isolated from digital life. Pew Research Center, 2014; http://www. pewinternet.org/2014/04/03/older-adults-and-technology-use/; retrieved February 2, 2017

7. Verdonck CM, Ryan S. Mainstream technology as an occupational therapy tool: Technophobe or technogeek? British Journal of Occupational Therapy 2008;71(6):253-256; https://doi. org/10.1177/030802260807100607

8. Ballantyne A, Trenwith L, Zubrinich S, Corlis M. I 
feel less lonely: What older people say about participating in a social networking website. Quality in Ageing \& Older adults 2010;11:25-35; https://doi. org/10.5042/qiaoa.2010.0526.

9. Aguilar A, Boerema C, Harrison J. Meanings attributed by older adults to computer use. Journal of Occupational Science 2010;17(1):27-33; https://doi.org/ 10.1080/14427591.2010.9686669

10. Nyman A, Isaksson G. Togetherness in another way: Internet as a tool for togetherness in everyday occupations among older adults. Scandinavian Journal of Occupational Therapy 2015;22(5):387-393; https:// doi.org/10.3109/11038128.2015.1020867

11. Leist AK. Social media use of older adults: A minireview. Gerontology 2013;59(4):378-84; https://doi. org/10.1159/000346818

12. Mullins LC, Sheppard HL, Andersson L. Loneliness and social isolation in Sweden: Differences in age, sex, labor force status, self-rated health, and income adequacy. Journal of Applied Gerontology 1991;10(4):455-68; https://doi. org/10.1177/073346489101000407

13. Dahlberg L, Andersson L, McKee K J, Lennartsson C. Predictors of loneliness among older women and men in Sweden: A national longitudinal study. Aging \& Mental Health 2015;19(5):409-17; https://doi.org/1 $0.1080 / 13607863.2014 .944091$

14. Goll JC, Charlesworth G, Scior K, Stott J. Barriers to social participation among lonely older adults: The influence of social fears and identity. Plos one 2015;10(2): e0116664; https://doi.org/10.1371/journal.pone.0116664

15. Stanley M, Moyle W, Ballantyne A, Jaworski K, Corlis M, Oxlade D, Stoll A, Young B. 'Nowadays you don't even see your neighbours': Loneliness in the everyday lives of older Australians. Health \& Social care in the Community 2010;18(4):407-414; https:// doi.org/10.1111/j.1365-2524.2010.00923.x

16. Cotten SR, Anderson WA, McCullough BM. Impact of internet use on loneliness and contact with others among older adults: Cross-sectional analysis. Journal of Medical Internet Research 2013;15(2):e39; https://doi.org/10.2196/jmir.2306

17. Tsai HH, Tsai YF. Changes in depressive symptoms, social support, and loneliness over 1 year after a minimum 3-month video conference program for older nursing home residents. Journal of Medical Internet Research 2011;13(4):e93; https://doi. org/10.2196/jmir.1678.

18. Nef T, Ganea RL, Müri RM, Mosimann UP. Social networking sites and older users: A systematic review. International Psychogeriatrics 2013;25(7):10411053; https://doi.org/10.1017/S1041610213000355

19. Larsson E, Nilsson I, Larsson-Lund M. Participation in social internet-based activities: Five seniors' intervention processes. Scandinavian Journal of Occupational Therapy 2013; 20(6):471-480; http://dx.doi.or g/10.3109/11038128.2013.839001

20. Larsson E, Padyab M, Larsson-Lund M, Nilsson I. Effects of a social internet-based intervention programme for older adults: An explorative randomised crossover study. British Journal of Occupational Therapy 2016;79(10):629-636; https://doi. org/10.1177/0308022616641701

21. Yuan S, Hussain SA, Hales KD, Cotten SR. What do they like? Communication preferences and patterns of older adults in the united states: The role of technology. Educational Gerontology 2016;42(3):163174; https://doi.org/10.1080/03601277.2015.108339 2

22. Craig P, Dieppe P, Macintyre S, Michie S, Nazareth I, Petticrew M. Developing and evaluating complex interventions: The new Medical Research Council guidance. BMJ 2008;337:a1655; https://doi. org/10.1136/bmj.a1655

23. Hammell KW. Using qualitative research to inform the client-centred evidence-based practice of occupational therapy. British journal of Occupational Therapy 2001;64(5):228-234; https://doi. org/10.1177/030802260106400504

24. Brinkmann S, Kvale S. Learning the craft of qualitative research interviewing. Third edition. Los Angeles: SAGE Publications, Incorporated 2015

25. Strauss A, Corbin J. Basics of qualitative researchtechniques and procedures for developing grounded theory. Second edition. Thousands Oaks, CA: SAGE Publications 1998

26. Lincoln VS, Guba EG. Naturalistic inquiry. Beverly Hills, CA: Sage Publications 1985

27. Krefting L. Rigor in qualitative research: The assessment of trustworthiness. American Journal of Occupational Therapy 1991;45(3):214-222; https://doi. org/10.5014/ajot.45.3.214

28. Mosey AC. Psychosocial components of occupational therapy. New York: Raven Press 1986

29. Law M, Baptiste S, Mills J. Client-centered practice: what does it mean and does it make a difference? Canadian Journal of Occupational Therapy 1995;62(5):250-257; https://doi. org/10.1177/000841749506200504

30. Fokkema T, Knipscheer K. Escape loneliness by going digital: A quantitative and qualitative evaluation of a Dutch experiment in using ECT to overcome loneliness among older adults. Aging \& Mental Health 2007;11(5):496-504; https://doi. org/10.1080/13607860701366129

31. Savikko N, Routasalo P, Tilvis R, Pitkälä K. Psychosocial group rehabilitation for lonely older people: favourable processes and mediating factors of the intervention leading to alleviated loneliness. International Journal of Older People Nursing 2010;5(1):16-24; https://doi.org/10.1111/j.1748-3743.2009.00191.x

32. Finlay L. Groupwork in occupational therapy. London, UK: Chapman \& Hall 1994

33. Forsyth DR. Group dynamics. $5^{\text {th }}$ edition. Belmont, CA: Wadsworth Cengage learning 2010

34. Guba EG. ERIC/ECTJ Annual Review Paper: Criteria for assessing the trustworthiness of naturalistic inquiries. Educational Communication and Technology 1981;29(2):75-91; https://doi.org/10.1007/ BF02766777

35. Lincoln YS. Emerging criteria for quality in qualitative and interpretive research. Qualitative Inquiry. 1995;1(3):275-289; https://doi. org/10.1177/107780049500100301 